\title{
Optic Chiasmatic Hypothalamic Glioma Presented as with Panhypopituitarism with Bilateral Primary Optic Atrophy
}

\author{
Al Amin $\mathrm{ASM}^{1}$, Afrin $\mathrm{S}^{2}$, Biswas $\mathrm{SK}^{3}$, Rahman $\mathrm{W}^{4}$, ${ }^{*}$ Hasan $\mathrm{MN}^{5}$
}

\begin{abstract}
Optic chiasmatic hypothalamic gliomas are among common primary neoplasm of the optic nerve. It presents with decreased vision as well as features of hypopituitarism due to infiltration of the hypothalamus. In this case report, a young man presented with loss of libido, increased thirst, gradual loss of vision, bilateral optic atrophy and visual field defect. The MRI of sellar and paraseller region showed optic chiasmatic glioma with hypothalamic extension and biochemical parameter showed panhypopituitarism. We diagnosed this patient as a case of Optic chiasmatic hypothalamic gliomas (OCHGS) with panhypopituitarism with partial cranial diabetes insipidus with bilateral primary optic atrophy. The patient underwent surgery after adequate hormonal treatment but died due to post-operative complications
\end{abstract}

Keywords: Optic chiasmatic glioma,hypothalamic glioma, panhypopituitarism, partial cranial diabetes insipidus.

\section{INTRODUCTION}

Optic chiasmatic hypothalamic gliomas (OCHGS) are one kind of benign tumors because of their histological appearance. It is an important subset of optic pathway

1. Dr. ASM Al Amin, Resident, Phase-A (MD), Department of Gastroenterology, Bangabandhu Sheikh Mujib Medical University (BSMMU), Shahbag, Dahaka- 1000.

2. Dr. Shanta Afrin, Resident, Phase-A (MD), Department of Critical Care Medicine, Dhaka Medical College, Dahka-1000.

3. Dr. Sunil Kumar Biswas, Professor, Department of Internal Medicie, BSMMU, Shahbag, Dahaka-1000.

4. Dr. Wahida Rahman, Junior Consultant, Department of Obstetrics and Gynaecology, 300 bed Hospital, Khanpur, Narayangonj, Dhaka.

5. *Dr. Md. Nazmul Hasan, Assistant Professor, Departemnt of Internal Medicine, BSMMU, Shahbag, Dahaka-1000,Email-nazmul_31st@yahoo.com

*For Correcpondence glioma. OCHGS are usually shown age-dependent behavior. Though, it is a benign tumor, the patients younger than five years and more than twenty years exhibit aggressive growth. It's difficult to differentiate the clinical behavior of such tumors because there are no specific pathological features. Some hypothalamic tumors can grow in the wall of the third ventricle and infiltrate the chiasm. So the distinguished point between the glioma either originates from the hypothalamus or from the chiasm that invades the hypothalamus secondarily is difficult to differentiate. Optic glioma has various kinds of presentation because of the proximity of the optic chiasm, hypothalamic-pituitary axis, and third ventricle. The pituitary gland is located at the base of the brain and very nearer to the hypothalamus. The pituitary gland has various functions within the body as it regulates the major endocrine secretion. The pituitary gland has two lobes, Anterior and posterior. The anterior pituitary is consists of hormone-producing epithelium and the posterior pituitary consists of nervous tissue. Decreased secretion of one or more than one hormone from all eight hormones known as hypopituitarism. The patient of OCGHS is frequently present with visual disturbances, active endocrinopathies, and, the features of the raised intracranial features. On fundoscopic examination optic atrophy is commonly found because of the damage of the optic nerve which carries impulses from the eye to the brain. It is the end stage of the disease process due to damage of the retinogeniculate portion of the visual pathway. Optic atrophy can be present with blurred vision and difficulties with peripheral vision and color vision. Presentation is variable between the child and adults. Sometimes children are presented with visual symptoms and adults are presented with endocrine symptoms earlier. ${ }^{1-4}$

\section{CASE REPORT}

A 22-year-old male came to the hospital due to the gradual dimness of vision, weight gain, decreased libido, polydypsia and polyuria for one year. The patient had no 
headache, convulsion and weakness of the limbs. The patient cannot concentrate on his study due to excessive fatigue ness. He has had a significant decrease in appetite and day to day activities for whom he consulted with a psychiatry doctor previously. The patient also has cold intolerance and constipation. He said he feels dizzy when he stands from a sitting position. On general examination shows an ill-looking, anxious man with dry and pale skin. Temperature 98F, Blood pressure- 100/60 on sitting and $85 / 50$ on standing, the pulse is $88 / \mathrm{min}$. Ophthalmologic evaluation showed visual acuity was reduced to perception of light and fundoscopy revealed bilateral primary optic atrophy. The systemic examination examination revealed no abnormality. The laboratory investigations are shown in the table-1. Perimetry could not be performed due to reduced visual acuity. Magnetic resonance imaging (MRI) of sellar and para sellar region showed optic chiasmal glioma with hypothalamic involvement. Considering all the evidence he was diagnosed as a case of hypothalamic optic chiasmatic glioma with panhypopituitarism with bilateral optic atrophy. He was treated with hormonal supplementation with thyroxine, intranasal desmopresine and prednisolone leads to improvement of his symptoms. Then a neurosurgeon was consulted and he decided to operate the patient. But, unfortunately he died after 2 days of surgery due to post- operative complication.

Table-1: Laboratory investigation profile of the patient.

\begin{tabular}{|c|c|c|}
\hline Investigation & Result & Reference \\
\hline \multirow[t]{2}{*}{ Complete blood count } & $\mathrm{Hb}: 9.1 \mathrm{gm} / \mathrm{dl}$ & Adult male: $15.0 \pm 2.0$ \\
\hline & RBC: $3.01 \mathrm{gm} / \mathrm{dl}$ & Male: $5.0 \pm 0.5$ \\
\hline \multirow[t]{2}{*}{ Serum Electrolytes } & $\mathrm{Na}^{+} 158 \mathrm{mmol} / \mathrm{l}$ & $137-157 \mathrm{mmol} / \mathrm{L}$ \\
\hline & $\mathrm{K}^{+} 3.70 \mathrm{mmol} / \mathrm{L}$ & $3.50-5.10 \mathrm{mmol} / \mathrm{L}$ \\
\hline Serum creatinine & $1.00 \mathrm{mg} / \mathrm{dl}$ & $0.3-1.4 \mathrm{mg} / \mathrm{dl}$ \\
\hline Free T3 & $1.71 \mathrm{pmol} / \mathrm{L}$ & $4.26-8.10 \mathrm{pmol} / \mathrm{L}$ \\
\hline Free T4 & $6.56 \mathrm{pmol} / \mathrm{L}$ & $10.4-19.6 \mathrm{pmol} / \mathrm{L}$ \\
\hline Serum TSH & $1.08 \mu \mathrm{IU} / \mathrm{ml}$ & $0.465-4.680 \mu \mathrm{IU} / \mathrm{ml}$ \\
\hline Serum FSH & $<0.66 \mu \mathrm{IU} / \mathrm{ml}$ & Male: $0.95-11.95$ \\
\hline Serum LH & $<0.216 \mu \mathrm{IU} / \mathrm{ml}$ & Male: $1.14-8.75$ \\
\hline Serum Prolactin & $463 \mu \mathrm{IU} / \mathrm{L}$ & Male: $78-380$ \\
\hline Basal cortisol & $49.91 \mathrm{nmol} / \mathrm{L}$ & $101.2-690.0 \mathrm{nmol} / \mathrm{L}$ \\
\hline Serum ACTH & $5.00 \mathrm{pg} / \mathrm{ml}$ & $8.3-57.8 \mathrm{pg} / \mathrm{ml}$ \\
\hline Serum Testosterone & $0.025 \mathrm{ng} / \mathrm{ml}$ & Male: $2.2-10.5 \mathrm{ng} / \mathrm{ml}$ \\
\hline \multicolumn{3}{|c|}{ Water deprivation test } \\
\hline \multicolumn{3}{|c|}{ After water deprivation } \\
\hline \multicolumn{3}{|c|}{ a)At 11.00 am } \\
\hline Serum osmolality & $346 \mathrm{~m} . \mathrm{osmol} / \mathrm{kg}$ & $285-295 \mathrm{~m} . \mathrm{osmol} / \mathrm{kg}$ \\
\hline Urine osmolarity & $176 \mathrm{~m} . \mathrm{osmol} / \mathrm{kg}$ & $300-900$ m.osmol/kg \\
\hline \multicolumn{3}{|l|}{ b)At $1.00 \mathrm{pm}$} \\
\hline Serum osmolality & $382 \mathrm{~m} . \mathrm{osmol} / \mathrm{kg}$ & $285-295$ m.osmol/kg \\
\hline Urine osmolality & $153 \mathrm{~m} . \mathrm{osmol} / \mathrm{kg}$ & $300-900$ m.osmol/kg \\
\hline \multicolumn{3}{|c|}{ c)At $1.50 \mathrm{pm}$ after administration of desmopressin } \\
\hline Serum osmolality & $354 \mathrm{~m} . \mathrm{osmol} / \mathrm{kg}$ & $285-295 \mathrm{~m} . \mathrm{osmol} / \mathrm{kg}$ \\
\hline Urine osmolality & $459 \mathrm{~m} . \mathrm{osmol} / \mathrm{kg}$ & $300-900$ m.osmol/kg \\
\hline
\end{tabular}




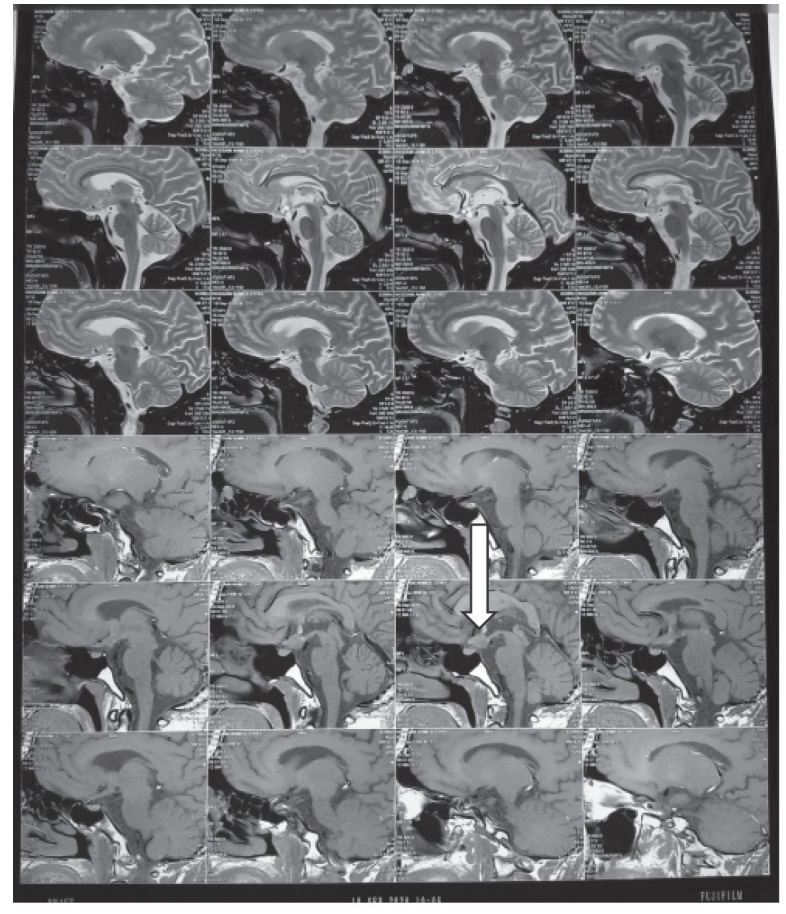

Figure 1: MRI of sellar and parasellar region $\mathrm{T} 1$ and $\mathrm{T} 2$ weighted image sagital view is showing optic chiasmal glioma with hypothalamic involvement.

\section{DISCUSSION}

Optic glioma is a tumor of childhood that can arise anywhere along the length of the optic pathway from the optic globe up to the occipital cortex including optic chiasma and hypothalamus. They constitute $2-6 \%$ of all intracranial tumors. ${ }^{5}$ Optic chiasmatic-hypothalamic gliomas (OCHGs) is considered as an important subset of optic pathway gliomas that is often referred to as a single disease entity because the tumor that arises in the chiasm has the potential to infiltrate the hypothalamus posteriorly and hypothalamic tumors that arises from the walls of the third ventricle can grow forward and infiltrate the optic chiasm. ${ }^{1,6,7}$ Histologically optic chiasmatic gliomas are low-grade astrocytomas and they are more invasive and aggressive than optic nerve gliomas. Although being relatively "benign" in histology, tumors can progress that can cause considerable morbidity in young children. ${ }^{1,6,7}$

Optic chiasmatic glioma tends to grow as a larger mass with symptoms, occur in very young children or older individuals. It may become large enough to affect the physiology of the hypothalamus and can present with endocrine abnormalities. The hypothalamic dysfunction by these lesions can present with manifestations of panhypopituitarism and also endocrine-active syndromes by secretion of hypothalamic-releasing factors from the tumors. When tumors affect the appropriate nuclei of the hypothalamus or the pituitary stalk can result in cranial diabetes insipidus due to impairment of antidiuretic hormone release. In this case study, a young boy was having OCHGs presented with panhypopituitarism and partial cranial diabetes insipidus which is consistent with the literature.

Optic chiasmatic glioma most commonly present as visual dysfunction associated with bitemporal field defects, and optic disc changes. Non-pulsatile proptosis, nystagmus, strabismus, and poor visual fixation are also common ophthalmological findings. Optic atrophy present on funduscopy. This tumor may also expand into the third ventricle and occludes the foramina of Munro that leads to the development of hydrocephalus with its feature. ${ }^{8-10}$ but can cause additional symptoms when it is large. Local involvement within the orbit can be characterized using CT, but MRI is superior in showing the intracranial extent of the lesion. Intracranial calcification in optic pathway glioma is rare. We present a rare case of optic pathway glioma with calcification in the intracranial component. Also, we describe MR spectroscopy (MRS

Patients may have neurological symptoms such as headaches, as well as eye pain, hemiplegia, and sometimes dementia. ${ }^{11}$

Our patient presented with gradually decreasing vision initially involving the left eye and then the right eye and gradually visual acuity came down to perception of light only. He also had bilateral primary optic atrophy on fundoscopic examination. Although, no neurological features were present.

The evaluation of patients with optic chiasmatic gliomas involves a thorough family history, careful assessment of visual status, evaluation for signs and symptoms of raised intracranial pressure from obstruction of the third ventricle, and assessment of the patient's endocrine status, as well as evaluation of both hypopituitarism and endocrine-active syndromes. ${ }^{7-10}$ The diagnostic evaluation consists of laboratory testing, including measurement of pituitary hormones, visual examination with measurement of acuity and visual fields, as well as imaging diagnosis. ${ }^{7-10}$ Magnetic resonance imaging (MRI) with gadolinium enhancement use for the most accurate delineation of the lesions involved. ${ }^{7-15} \mathrm{After}$ appropriate investigations our patient was diagnosed as a case of hypothalamic optic 
chiasmatic glioma with panhypopituitarism with bilateral optic atrophy.

Management strategies for visual pathway gliomas include observation, surgery, chemotherapy, irradiation, and a combination of these modalities. Radiation has been the standard therapy for the progressive expansion of tumors. 12 Treatment should be according to the hormonal deficiencies. Radiation therapy may have some serious adverse effects including optic nerve injury, endocrinopathy, vasculopathy, and radiation- induced second neoplasms. ${ }^{12}$ Our patient had features of panhypopituitarism, so, he was treated with hormonal supplementations with both clinical and biochemical improvement of the symptoms. Then we discussed with neurosurgical team and endocrinology for the further course of management. The whole team decided that surgical removal of the tumor would be the best option and he was operated afterwards. But, despite all efforts he died due to post-operative complications.

\section{CONCLUSIONS}

Optic chiasmatic-hypothalamic gliomas is rare tumor of optic nerve which can also invole hypothalamus. Patient may present with endocronopathy,optic atrophy and diverse neurological manifestations. Early detection of the tumor is very important because it could be potentially vision threatening in other word could be life threatening.

\section{REFERENCES}

1. Alshail E, Bs MB, Rutka JT, Ph D, Becker LE, Hoffman HJ. Optic Chiasmatic-Hypothalamic Glioma.Bain Pathol. 1 997:799-806

2. Quigley HA, Anderson DR. The histologic basis of optic disk pallor in experimental optic atrophy. Am J Ophthalmol. 1977;83(5):709-17

3. Thompson CJ, Costello RW, Crowley RK. Management of hypothalamic disease in patients with craniopharyngioma. Clin Endocrinol (Oxf). 2019 ;90(4):506-16.

4. Helmut W, Martin S. Diagnostik und Therapie der Optikusneuritis. Dtsch Arztebl Int. 2015;112(37): 616-26

5. Silva MM, Goldman S, Keating G, Marymont MA, Kalapurakal J, Tomita T. Optic pathway hypothalamic gliomas in children under three years of age: The role of chemotherapy. Pediatr Neurosurg. 2000;33(3): $151-8$

6. Varan A, Batu A, Cila A, Soylemezoğlu F, Balc S, Akalan $\mathrm{N}$, et al. Optic glioma in children: A retrospective analysis of 101 cases. Am J Clin Oncol Cancer Clin Trials. 2013;36(3):287-92

7. Ater J, Tarbell N, Jr EL. Optic nerve, chiasmal, and hypothalamic tumors. Cancer Nerv Syst ed 2002; $158-70$

8. Pungavkar SA, Lawande MA, Patkar DP, Agrawal N V., Gadani S. Bilateral optic pathway glioma with intracranial calcification: Magnetic resonance imaging and magnetic resonance spectroscopy findings. Australas Radiol. 2005;49(6):489-92

9. Shapey J, Danesh-Meyer H V., Kaye AH. Diagnosis and management of optic nerve glioma. J Clin Neurosci [Internet]. 2011;18(12):1585-91

10. Smith MM, Strottmann JM. Imaging of the optic nerve and visual pathways. Semin Ultrasound CT MRI. 2001;22(6):473-87.

11. Lambiase A, Sacchetti M, Aronni S, Bonini S. Aggressive Glioma.Arch Ophthalmol. 2005;123 (May):694-700.

12. Rosenstock JG, Packer RJ, Bilaniuk L. Chiasmatic optic glioma treated with chemotherapy. A preliminary report. J Neurosurg. 1985;63(6):802-66. 